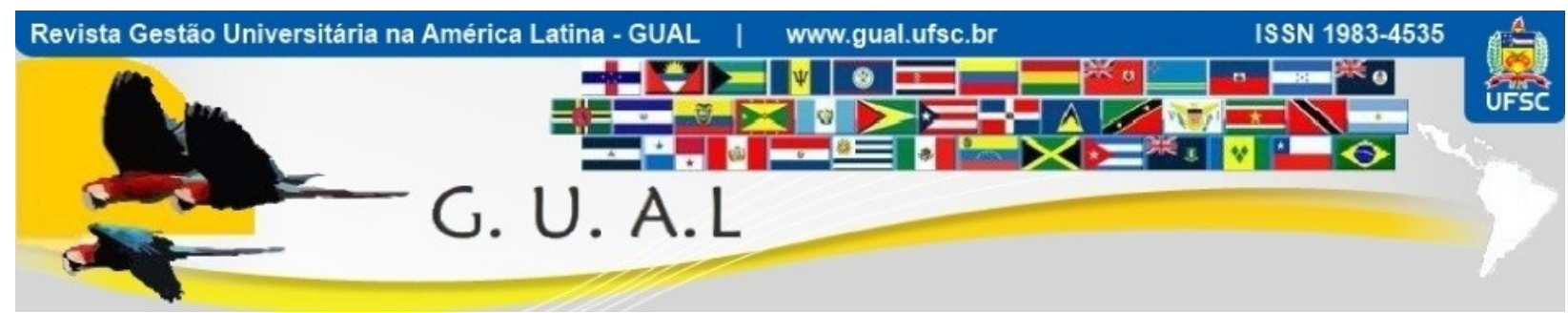

DOI: http://dx.doi.org/10.5007/1983-4535.2013v6n1p83

\title{
AS MUDANÇAS LEGAIS NO AMBIENTE INSTITUCIONAL DO SETOR DE EDUCAÇÃO E AS ESTRATÉGIAS DE CRESCIMENTO DE UMA INSTITUIÇÃO DE ENSINO SUPERIOR
}

\author{
CHANGES IN THE LEGAL ENVIRONMENT OF INSTITUTIONAL SECTOR \\ EDUCATION AND GROWTH STRATEGIES OF AN INSTITUTION OF HIGHER \\ EDUCATION
}

Renata Massoli Borges, Mestre Universidade Federal de Santa Catarina - UFSC renatamassoli@hotmail.com

Gustavo Rossa Camelo, Mestre Universidade Federal de Santa Catarina - UFSC gustavorcamelo@hotmail.com

André Luís da Silva Leite, Doutor Universidade Federal de Santa Catarina - UFSC andre 1eite@hotmail.com

Gabriela Gonçalves Silveira Fiates, Doutora Universidade Federal de Santa Catarina - UFSC gabriela.fiates@ufsc.br

Álvaro Guillermo Rojas Lezana, Doutor Universidade Federal de Santa Catarina - UFSC lezana@deps.ufsc.br

Recebido em 05/julho/2012

Aprovado em 26/outubro/2012

Sistema de Avaliação: Double Blind Review

Esta obra está sob uma Licença Creative Commons Atribuição-Uso. 


\title{
RESUMO
}

O objetivo deste estudo é analisar a relação das mudanças legais no ambiente institucional do setor de educação superior nas estratégias de crescimento de uma Instituição de Ensino Superior. A pesquisa é um estudo de caso da mantenedora CEAMA que abrange de 1996, mudanças na lei e expansão de IES privadas, e, de 2000 a 2010 - 10 anos de funcionamento da Instituição de Ensino Superior, seu processo de mudanças e crescimento. Utilizou-se de dados primários junto às pessoas relacionadas diretamente com o ambiente pesquisado, através de um roteiro de entrevista, o que permitiu compreender em profundidade o tema e o cenário pesquisado e, também, de dados secundários disponibilizados pela própria IES e normas da educação superior. Os resultados da análise entre a relação das mudanças no ambiente institucional do setor de educação superior com as estratégias de crescimento da Instituição de Ensino Superior CEAMA indicaram que existe uma relação de influência, visto que o ambiente é composto de regras que determinam como as IES devem se comportar no ambiente.

Palavras-chave: Ambiente institucional. Instituição de ensino superior. Mudanças. Estratégia de crescimento.

\begin{abstract}
The aim of this study is to analyze the changes legal in the institutional environment of the higher education sector in the growth strategies of an Institution of Higher Education. The research is a study of case covering the maintainer CEAMA 1996, changes in law and expansion of private higher education institutions, and from 2000 to $2010-10$ years of operation of the Institution of Higher Education, the process of change and growth. We used primary data from the people directly related to the environment studied, using a structured interview, which allowed us to understand in depth the theme and scenario investigated, and also secondary data provided by the Institution of Higher Education itself and standards of higher education. The results of the analysis of the relationship between changes in institutional environment of the higher education sector and the growth strategies of the Higher Education Institution CEAMA indicated that there is a relationship of influence, since the environment is composed of rules that determine how Institutions of Higher Education should behave in the environment.
\end{abstract}

Keywords: Institutional environment. Institution of higher learning. Changes. Growth strategy. 


\section{INTRODUÇÃO}

O sistema de educação superior brasileiro experimentou, a partir da segunda metade da década de 1990, significativo crescimento, especialmente devido ao crescimento no número de Instituições de Ensino Superior (IES) privadas. A partir deste período, o ensino superior privado no Brasil passou a absorver mais da metade das matrículas do país, mesmo sob um alto grau de regulamentação (CASTRO, 2010).

A participação da iniciativa privada no setor de educação superior cresceu rapidamente, porém encontra resistências junto às autoridades reguladoras, devido a receios em relação à sua qualidade. Adicionalmente, começam a aparecer dificuldades para atrair alunos que possam pagar os seus preços. A legislação brasileira só recentemente começou a trazer possibilidades de flexibilização em relação ao modelo tradicional de universidade, permitindo maior acesso ao ensino superior privado (BARRETO; SCHWARTZMAN, 2010). $\mathrm{O}$ rápido crescimento do número de Instituições de Ensino Superior no Brasil, especialmente das IES privadas nas últimas décadas, estimula estudos, pesquisas e reflexões sobre a dinâmica desse progresso e sua influência no desenvolvimento educativo do país.

Porto e Régnier (2003) afirmam que as tendências e mudanças que o ambiente de atuação do ensino superior tem passado apontam para uma quebra de paradigmas com consequências ainda não vislumbradas na sua totalidade. Para os autores, porém, o perfil ou o contorno do que virá a ser o universo do ensino superior brasileiro no futuro será definido, essencialmente, pela evolução dos seguintes aspectos: (1) a natureza das forças externas de transformação que incidem sobre seu campo de atuação (macroambiente e suas forças econômicas, sociais, demográficas, tecnológicas, políticas); (2) as mudanças internas no campo (incluindo o jogo de forças entre os atores e suas disputas de poder e conquista de espaço); e (3) os resultados que estas transformações produzem como externalidades (novos serviços, formas de ação, etc.) que, por sua vez, incidem sobre o ambiente econômico, social, político, etc., realimentando o ciclo (PORTO; RÉGNIER, 2003).

Dessa forma, a dinâmica do ambiente tem implicações diretas sobre o desempenho das IESs, que, por sua vez, para resistirem neste ambiente mediante tal agitação, necessitam aprimorar constantemente seus processos, canalizando esforços para a otimização de seus recursos. As pressões para mudança e /ou adaptação vêm tanto do mercado, cada vez mais competitivo, quanto das instituições que regulamentam o setor, especialmente o Ministério da Educação e Cultura (MEC) (ESTEVES, 2007). 
Posto isto, o objetivo deste artigo é analisar a relação das mudanças legais ocorridas no ambiente institucional do setor de educação superior com as estratégias de crescimento de uma IES.

Para atingir o objetivo, o artigo está organizado em 4 seções, Fundamentação Teórica, Procedimentos Metodológicos, Apresentação e Resultados da Pesquisa e Conclusões.

\section{AMBIENTE INSTITUCIONAL}

Nos últimos quarenta anos, as pesquisas sobre estratégia têm ganhando robustez, especialmente visando à compreensão das fontes de vantagem competitiva das empresas. De fato, tais pesquisas estão à procura de quais as fontes de desempenho diferencial, ou seja, do porquê de umas empresas serem bem sucedidas enquanto outras falham (SCHNEIDER et al, 2009). Segundo Carnall (1995), em um mundo de mudanças, a única constante é a mudança. Fischer (2001, p. 2) enfatiza que "a discrepância entre velocidade das mudanças do ambiente do setor e a velocidade das mudanças do ambiente interno da organização impõe a assustadora tarefa da mudança organizacional".

As principais escolas de estratégia, de alguma forma, visam a relacionar a firma com o ambiente no qual ela encontra-se inserida. $\mathrm{O}$ ambiente importa, já que a firma não desenvolve estratégias no vazio. Vislumbrado como mero conjunto de pressões técnicas e econômicas pelos adeptos da abordagem da escolha estratégica ou como conjunto de dimensões abstratas pelos partidários da abordagem cognitiva, o ambiente ganha real importância somente no corpo das teorias contemporâneas, cujas ideias se estendem à geração de estratégias (Fonseca\& Machado-da-Silva, 2002). Conforme colocam Mintzberg (2003), o ambiente se torna ator na explicação dos fenômenos organizacionais.

Assim, como colocam Fonseca e Machado-da-Silva (2002), dentre as perspectivas de análise, destaca-se a abordagem institucional, na qual o ambiente é definido como repositório de redes relacionais e de sistemas culturais, compostos por valores, crenças e regras, que transmitem conceitos sobre modos apropriados de fazer e de agir. A conformação a tais fatores normativos garante suporte de legitimação à organização, e, ao longo do tempo, a sua reprodução conduz à convergência de estruturas e estratégias no interior de um mesmo setor social (FONSECA; MACHADO-DA-SILVA, 2002), e, se as organizações dentro do campo organizacional são bem sucedidas, a partir do qual têm buscado legitimidade (por meio de conformidade às pressões isomórficas geradas por estas instituições) são sancionadas como 


\section{AS MUDANÇAS LEGAIS NO AMBIENTE INSTITUCIONAL DO SETOR DE EDUCAÇÃO E AS \\ ESTRATÉGIAS DE CRESCIMENTO DE UMA INSTITUIÇÃO DE ENSINO SUPERIOR \\ DOI: http://dx.doi.org/10.5007/1983-4535.2013v6n1p83}

tendo sido responsável por dar origem a tais organizações de sucesso, mas, na realidade, o sucesso de organizações poderia ser dependente de vários outros fatores internos ou externos (RIAZ, 2009).

De acordo com as idéias de Vasconcelos e Cyrino (2000), as mudanças nas condições ambientais frequentemente exigem das organizações uma regeneração da sua base de recursos e competências. Com a alteração das condições ambientais, mudam, também, os recursos essenciais necessários para garantir a sobrevivência e a performanceeconômica diferenciada das firmas. Para os autores, a noção de estratégia é fortemente orientada em direção à noção de adaptação. É a partir da análise objetiva de seu ambiente que a firma será capaz de identificar a posição mais favorável. Assim, a escolha da estratégia correta permitirá à firma adaptar-se à estrutura da indústria. A estratégia deve ser internamente coerente, adaptando os elementos internos da firma à sua posição na indústria e as atividades da firma devem, dessa maneira, ser configuradas de maneira coerente, cada uma dando suporte e complementando a outra.

No campo dos estudos organizacionais, a teoria institucional é uma das principais vertentes a admitir a importância da visão de mundo, ou dos esquemas interpretativos, como fator interveniente na produção de decisões e ações que conduzem a mudanças organizacionais, ou à resistência às mudanças. A teoria institucional geralmente se concentra na explicação das origens sociais das ações de atores tomados, em princípio, como indivíduos que não agem isoladamente (CRUBELLATE; GRAVE; MENDES, 2004).

A Teoria Institucional, segundo Zucker (1987) pressupõe que a influência sobre as organizações é exercida por grupos ou normas sociais, tanto internas, quanto externas. Desse modo, as estratégias adotadas pela organização, nesse sentido, podem ser compreendidas como conseqüências dos padrões institucionalizados no ambiente organizacional. Esses padrões podem ser influenciados por mecanismos coercitivos, normativos ou miméticos (DIMAGGIO; POWELL, 2007). Neste sentido, a Teoria Institucional pode ser interpretada, em certo grau, como uma abordagem mais próxima do determinismo.

Na mesma perspectiva, Crubellate, Grave e Mendes (2004) dizem que essa vertente vai muito além da simples sugestão de que as organizações se adaptam a ambientes institucionais. Eles sugerem que há um processo de mútua construção e reconstrução entre ambiente e organizações, sendo a estratégia importante elemento, não somente de intermediação como também de construção do ambiente e dos agentes envolvidos. Ou seja, é 


\section{AS MUDANÇAS LEGAIS NO AMBIENTE INSTITUCIONAL DO SETOR DE EDUCAÇÃO E AS \\ ESTRATÉGIAS DE CRESCIMENTO DE UMA INSTITUIÇÃO DE ENSINO SUPERIOR \\ DOI: http://dx.doi.org/10.5007/1983-4535.2013v6n1p83}

possível estabelecer uma relação de influência do ambiente sobre a firma, mas, em certa medida, esta última também pode influenciar o ambiente no qual encontra-se inserida.

Scott (2001) caracteriza que a perspectiva institucional está baseada em pressuposto realista, quanto à natureza do social, e em visão das instituições enquanto sistemas regulativos, intencionalmente projetados. Tais instituições possuem, portanto, papel positivo na sociedade, uma vez que possibilitam a ação estratégica. Selznick (1957) descreve que, tanto no velho quanto no novo institucionalismo, o reconhecimento de lógica interna das organizações, é relevante para o processo de adaptação, como se depreende da discussão sobre o papel da liderança organizacional.

De acordo com idéias de Crubellate, Grave e Mendes (2004), o novo institucionalismo, assim, fez voltar o foco da teoria institucional em organizações para o fenômeno da difusão de estruturas e comportamentos (DIMAGGIO; POWELL, 2007), como respostas a incertezas em face da realidade complexa. Um dos pressupostos centrais dessa perspectiva é o de que a realidade é socialmente definida e construída, na medida em que os agentes sociais interagem e definem para si, por processos pouco conscientes ou intencionais, o significado do mundo circundante. As instituições são compreendidas como definidoras de nossa visão de mundo e, com isso, importantes influenciadoras do comportamento social.

Assim, o novo institucionalismo apresenta dois rumos: um predominantemente cognitivista, que busca revelar, no processo de institucionalização, a tendência à repetição de significados sociais; e outro que admite a possibilidade de que instituições adquiram, também, aspecto formal, crescentemente externo e desconectado de qualquer significado original. Parece possível reconhecer que a perspectiva predominantemente cognitivista de institucionalização passou a admitir as instituições como determinantes da ação (comportamento e significado), enquanto a perspectiva intermediária manteve ainda entendimento mais próximo ao de Selznick no tocante ao papel social das estruturas e processos institucionalizados (CRUBELLATE; GRAVE; MENDES, 2004).

De acordo com essa perspectiva, as opções estratégicas e as intenções de controle da organização seriam entendidas como originárias da ordem institucional em que uma empresa se vê inserida e não dentro de uma lógica de eficiência e eficácia (ALPERSTEDT; MARTIGNAGO; FIATES, 2006).

Os padrões institucionalizados acabam influenciando as opções com que se deparam os tomadores de decisão, uma vez que suas decisões são produto de suas interpretações que, 
por sua vez, são baseadas em suas crenças e valores socialmente construídos a partir de suas interações sociais (MACHADO-DA-SILVA; FONSECA, 1999; MACHADO-DA-SILVA; FONSECA; FERNANDES, 1999). Assim, os decisores organizacionais mesmo quando pensam estar agindo conforme padrões lógicos e racionais podem, de fato, estar apenas seguindo padrões interpretados como racionais influenciados pelo ambiente institucional como respostas racionais à determinada situação (CRUBELLATE; GRAVE; MENDES, 2004).

Alperstedt, Martignago e Fiates (2006) afirmam que, em muitas universidades, a descentralização do poder, a autonomia profissional, a estrutura complexa e a intervenção governamental nos negócios internos das instituições acabam tornando a visão convencional de formulação de estratégias pouco adequada.

Assim, Machado-da-Silva, Fonseca e Fernandes (1999) afirmam que o ambiente institucional é onde se formam e difundem regras e padrões de procedimentos, que proporcionam à organização legitimidade e apoio contextual. Para Farina, Azevedo e Saes (1997), o ambiente é mutável no tempo - por forças internas ou externas ao seu próprio nível de análise, sendo que a principal contribuição da corrente de Ambiente Institucional tem sido o estabelecimento da relação entre instituições e desenvolvimento econômico. Ela se dedica mais especificamente ao estudo das regras do jogo, sendo que o ponto de partida da corrente de Ambiente Institucional é o reconhecimento de um trade-offentre especialização e custos de transação. A fim de se analisar esse papel das instituições, a corrente de Ambiente Institucional vem trilhando dois caminhos: a) investigar os efeitos de uma mudança no ambiente institucional sobre o resultado econômico ou b) teorizar sobre a criação das instituições.

Farina, Azevedo e Saes (1997, p. 61-62) afirmam que "o ambiente institucional fornece o quadro fundamental de regras que condiciona o aparecimento e seleção de formas organizacionais que comporão a estrutura de governança”.

\subsection{O AMBIENTE DAS INSTITUIÇÕES DE ENSINO SUPERIOR PRIVADAS}

Lisita e Peixoto (2001) colocam que a LDB no 9.394/1996 foi aprovada em um contexto caracterizado, principalmente, por uma rearticulação liberal, conservadora e balizada pela defesa do ideário da flexibilização, desregulamentação, privatização e, 
conseqüentemente, da reverência ao mercado. Cabendo a este o papel de regulador e condicionante das estratégias e diretrizes das IES.

De acordo com a Cartilha - Instituições Privadas de Ensino Superior (2010), as instituições de ensino superior brasileiras públicas e privadas são submetidas a diferentes procedimentos de criação e credenciamento. O credenciamento concedido pelo poder público é temporário conforme estabelece a LDB no 9.394/1996. Por isso existe a necessidade de recredenciamento da instituição após as avaliações realizadas no contexto do Sistema Nacional de Avaliação da Educação Superior (SINAES).

É o ato formal da autoridade governamental competente, que permite a uma instituição de ensino superior implantar e oferecer um curso superior de graduação (bacharelado, licenciatura), superior de tecnologia (tecnólogo) ou sequencial. $\mathrm{O}$ ambiente em que se insere o ensino superior sofreu grandes transformações, nos últimos anos, afetando em diferentes graus as instituições de ensino e as pessoas. Segundo Moraes (2001), além dos fatores do ambiente externo que geram impactos nas Instituições de Ensino Superior, as instituições enfrentam problemas decorrentes de sua própria inércia, da acirrada competição e da intervenção normativa do Estado, tanto na sua organização quanto no seu funcionamento.

Sendo assim, fica evidente que o ambiente das Instituições de Ensino Superior Privadas, juntamente com outros atores, exerce funções que viabilizam ou não o funcionamento das Instituições de Ensino Superior, são eles: as mantenedoras, os órgãos de regulação, os consultores e as associações de classe (MOISÉS FILHO, 2006).

\section{PROCEDIMENTOS METODOLÓGICOS}

Este estudo foi desenvolvido com base na lógica dedutiva, utilizando-se a pesquisa bibliográfico-documental e dados primários oriundos de entrevistas com dirigentes da IES estudada. A lógica da pesquisa é dedutiva, pois, neste caso, tal método sustenta os estudos que abordam a realidade, a partir de teorias, leis e posteriormente aplicados em casos particulares.

Assim, o processo da pesquisa caracteriza-se como qualitativo porque "[...] é mais subjetivo e envolve examinar e refletir as percepções para obter um entendimento de atividades sociais e humanas" (COLLINS; HUSSEY, 2005, p. 26).

Quanto aos fins - os objetivos da pesquisa - foi considerada como uma pesquisa Descritiva e Explicativa, uma vez que a pesquisa pretende descrever as estratégias da IES pesquisada, bem como as variáveis do ambiente institucional e, sobretudo, estabelecer 
relações entre o ambiente institucional e as estratégias desenvolvidas pela IES. Quanto aos meios, a estratégia de pesquisa caracteriza-se como um Estudo de Caso. O horizonte de tempo é Longitudinal. O estudo longitudinal é aquele no qual os dados são coletados ao longo do tempo, com obtenção sistemática e lenta de resultados. Desta forma, o estudo analisará (de 1996 a 1999 - mudança na lei e expansão de IES privadas; e de 2000 a 2010 - 10 anos de funcionamento da IES), as estratégias da IES.

\subsection{DEFINIÇÃO DAS VARIÁVEIS DE ANÁLISE}

Os dados utilizados são primários e secundários. Os dados primários tiveram como origem uma série de entrevistas semi-estruturadas com gestores da IES. Como fontes de dados secundários destacam-se: Plano de Desenvolvimento Institucional - PDI e Projeto Político Pedagógico Institucional - PPPI, disponíveis no site da IES e, também, impresso. A IES estudada denomina-se FAMA, localizada em São Luís (MA) e é constituída sob a forma de sociedade civil de direito privado, de natureza educacional e cultural, credenciada através da Portaria Ministerial $n^{\circ}$. 221, de 23 de fevereiro de 2000, publicada no D.O.U. de 25 de fevereiro de 2000 , e teve sua inauguração em $1^{\circ}$ de março de 2000.

\subsection{COLETA E ANÁLISE DE DADOS}

Para esta pesquisa foram utilizados fundamentalmente documentos da própria organização e dados primários de entrevistas com a Diretoria Geral, Diretoria Acadêmica, Diretoria Administrativa e Comissão Própria de Avaliação. A coleta dos dados secundários foi realizada a partir de um estudo sobre a LDB No 9.394/ 1996 e demais normas da educação superior disponíveis no site do MEC, materiais informativos disponibilizados pela IES e, também, através de documentos organizacionais. O exame do material disponível serviu como base para os próximos passos a serem desenvolvidos e para a montagem do contexto e da história de vida da organização estudada, caracterizando o ambiente objetivo em que ela se desenvolveu.

Após realizar as entrevistas, que foram gravadas e transcritas, foi realizada uma análise do relato das mesmas, uma vez que é no momento da utilização dos dados que o pesquisador transforma levantamento realizado em conhecimento aplicado (WOLCOTT, 1994). Para tanto, optou-se pela análise de conteúdo, conforme Bardin (2002). 


\section{MUDANÇAS NO AMBIENTE INSTITUCIONAL DO ENSINO DE EDUCAÇÃO SUPERIOR}

A nova Lei de Diretrizes e Bases da Educação Nacional, Lei $n^{\circ} 9.394$ de 20 de Dezembro de 1996, que estabelece as diretrizes e bases da educação nacional, permitiu o aumento significativo da participação do setor privado na educação superior. Esta LDB serviu como orientadora para os procedimentos acadêmicos das Instituições de Ensino Superior. Também traçou as diretrizes necessárias para o bom funcionamento da IES e serviu de base para que as IES elaborassem seu Plano de Desenvolvimento Institucional - PDI e o seu Projeto Político Pedagógico Institucional - PPPI, documentos essenciais para o funcionamento de uma IES que deseja formar cidadãos responsáveis e profissionais competentes para o mercado de trabalho. Assim, a LDB acabou dando mais autonomia às IES particulares e incentivando o surgimento de novas IES.

A Resolução CNE/CES n ${ }^{\circ} 1$ de 03 de abril de 2001, que estabeleceu normas para os cursos de pós-graduação, foi à balizadora para implantação de cursos de pós-graduação que iniciaram exatamente neste ano na FAMA, logo, já começou tendo esta resolução como norte. No mesmo ano, a Resolução $\mathrm{n}^{\circ} 2517$ de 22 de novembro de 2001 que já foi revogada, deu o norte para que o início do primeiro Censo no sistema do SIEd-Sup. A FAMA teve que ter o cuidado nas informações prestadas para que cruzassem com as já informadas ao MEC constantes no sistema.

Em 2002, a Resolução CNE/CES nº 10 de 11 de Março de 2002, hoje já revogada, dispõe sobre o credenciamento, transferência de mantença, estatutos e regimentos de instituições de ensino superior, autorização de cursos de graduação, reconhecimento e renovação de reconhecimento de cursos superiores, normas e critérios para supervisão do ensino superior do Sistema Federal de Educação Superior. Serviu de base orientadora para reconhecimentos dos cursos de graduação em 2004.

No final de 2002, a Resolução CNE/CP n 3 de 18 de Dezembro de 2002 institui as Diretrizes Curriculares Nacionais Gerais para a organização e o funcionamento dos cursos superiores de tecnologia. Serviu de base orientadora para elaboração dos Projetos Pedagógicos dos Cursos Tecnológicos que em 2010 foram autorizados pelo MEC e se iniciarão em 2011.

Uma das leis que marcou o ano de 2004 foi a Lei no 10861 de 14 de Abril de 2004 que instituiu o Sistema Nacional de Avaliação da Educação Superior - SINAES. A Lei do 


\section{AS MUDANÇAS LEGAIS NO AMBIENTE INSTITUCIONAL DO SETOR DE EDUCAÇÃO E AS \\ ESTRATÉGIAS DE CRESCIMENTO DE UMA INSTITUIÇÃO DE ENSINO SUPERIOR \\ DOI: http://dx.doi.org/10.5007/1983-4535.2013v6n1p83}

SINAES veio ampliar a avaliação institucional que já era feita desde 2002, ou seja, ampliou o raio de ação desde que definiu as dimensões a serem trabalhadas dentro da IES, assim como os indicadores necessários ao processo de Avaliação Institucional, o que obrigou cada IES a criar sua Comissão Própria de Avaliação - CPA.

Um fato marcante que representou mudança no ambiente foi a Instrução Normativa SRF n ${ }^{\circ} 456$ de 05 de Outubro de 2004, onde dispõe sobre a isenção do imposto de renda e de contribuições, aplicável às instituições que aderirem ao Programa Universidade para Todos. Quanto a essa Instrução Normativa SRF, as IES privadas que aderirem ao PROUNI são isentas as IES particulares de "Tributos Federais". A mecânica do programa funciona com o fornecimento de bolsas integrais e parciais em quantidade calculada semestralmente através de parâmetros fornecidos pelo MEC, através de portaria. Assim sendo, tecnicamente não é uma isenção, mas, sim, uma troca.

Ainda em 2004, a Portaria no 4361 de 29 de Dezembro de 2004 dispõe que os processos de credenciamento e recredenciamento de instituições de educação superior (IES), credenciamento para oferta de cursos de pós-graduação lato sensu, credenciamento e recredenciamento de instituições de educação superior, entre outros. Esta portaria aumentou a cobrança às IES Privadas para o seu processo de autorização de cursos e outros procedimentos, definiu as diretrizes para elaboração do primeiro Plano de desenvolvimento Institucional - PDI, quando houve a necessidade de envolver toda a comunidade acadêmica para traçar políticas para o ensino, para a pesquisa e para a extensão.

Em 2005, surge a Portaria $n^{\circ} 2413$ de 07 de Julho de 2005, que dispõe sobre a renovação de reconhecimento de cursos de graduação e de tecnologia. Esta Portaria serviu de base orientadora para a solicitação da renovação de reconhecimento de todos os cursos de graduação, o que a FAMA obteve pleno êxito nesse processo, considerando que foram atendidas plenamente todas as exigências da Portaria.

O Parecer CNE/CES n ${ }^{\circ} 91$ de 10 de abril de 2008 faz consulta sobre cobrança de taxas pela emissão de diploma de graduação feita por Instituição de Ensino Superior. Segundo informações da própria IES, tal parecer abalou profundamente as finanças da FAMA, uma vez que não estava no orçamento o pagamento dessa taxa cobrada pela Universidade Federal do Maranhão - UFMA para o registro dos diplomas, pois, até a data desse Parecer, eram os alunos que pagavam pelo diploma. Isso causou e causa até hoje um acúmulo muito grande de diplomas a serem enviados à UFMA para registro, pois a FAMA não tem orçamento para 
mandar todos os diplomas de uma só vez, o que envolveria muito dinheiro. Foi decidido mandar apenas 100 diplomas por mês para serem registrados por ordem de solicitação do aluno na Central de Atendimento. Isso tem causado um grau de insatisfação muito grande entre os graduados que esperam mais de seis meses para terem seu diploma registrado.

De acordo com as informações acima, a Figura 1 mostra os 10 eventos principais que influenciaram as estratégias da FAMA.

\begin{tabular}{|c|c|c|c|c|}
\hline \multicolumn{2}{|c|}{$\begin{array}{l}\text { MUDANÇAS DO } \\
\text { AMBIENTE } \\
\text { INSTITUCIONAL }\end{array}$} & IMPACTO NA IES & $\begin{array}{l}\text { ESTRATÉGIA DA } \\
\text { IES }\end{array}$ & $\begin{array}{l}\text { RESULTADO NA } \\
\text { IES }\end{array}$ \\
\hline 1 & $\begin{array}{l}\text { LDB N }^{\circ} 9.394, \text { de } \\
20 / 12 / 1996\end{array}$ & $\begin{array}{l}\text { Facilidade de abertura e } \\
\text { ampliação da IES }\end{array}$ & $\begin{array}{c}\text { Surgimento e } \\
\text { Expansão Geográfica }\end{array}$ & Criação da IES \\
\hline 2 & $\begin{array}{l}\text { RESOLUÇÃO } \\
\text { CNS/ CES No } 1 \\
\text { DE } 03 / 04 / 2001\end{array}$ & $\begin{array}{l}\text { Abertura para implantação de } \\
\text { cursos de pós-graduação }\end{array}$ & $\begin{array}{l}\text { Combinação } \\
\text { horizontal }\end{array}$ & Pós-graduação \\
\hline 3 & $\begin{array}{c}\text { RESOLUÇÃO N } \\
2517 \mathrm{DE} \\
22 / 11 / 2001 \\
\end{array}$ & $\begin{array}{l}\text { Informações foram cruzadas com } \\
\text { as já informadas ao MEC }\end{array}$ & Desenvolvimento & $\begin{array}{c}1^{\circ} \text { Censo no } \\
\text { Sistema SIEd-Sup }\end{array}$ \\
\hline 4 & $\begin{array}{l}\text { RESOLUÇÃO } \\
\text { CNE/ CES N }{ }^{\circ} 10 \\
\text { DE } 11 / 03 / 2002\end{array}$ & $\begin{array}{l}\text { Orientadora para reconhecimentos } \\
\text { dos cursos de graduação em } 2004\end{array}$ & Diversificação & $\begin{array}{l}\text { Credenciamento, } \\
\text { Reconhecimento e } \\
\text { Renovação }\end{array}$ \\
\hline 5 & $\begin{array}{c}\text { RESOLUÇÃO } \\
\text { CNE/ CP N } 3 \text { DE } \\
18 / 12 / 2002\end{array}$ & $\begin{array}{l}\text { Orientadora para elaboração dos } \\
\text { Projetos Tecnólogos }\end{array}$ & Diversificação & Cursos Tecnólogos \\
\hline 6 & $\begin{array}{c}\text { LEI N }^{\circ} 10861 \mathrm{DE} \\
14 / 04 / 2004\end{array}$ & Ampliar a avaliação institucional & Desenvolvimento & SINAES \\
\hline 7 & $\begin{array}{c}\text { INSTRUÇÃO } \\
\text { NORMATIVA } \\
\text { SRF No } 456 \text { DE } \\
05 / 10 / 2004 \\
\end{array}$ & $\begin{array}{c}\text { Isenção do imposto de renda e de } \\
\text { contribuições }\end{array}$ & Sobrevivência & ProUni \\
\hline 8 & $\begin{array}{l}\text { PORTARIA N }{ }^{\circ} \\
4361 \mathrm{DE} \\
29 / 12 / 2004 \\
\end{array}$ & $\begin{array}{l}\text { Aumento da cobrança para o } \\
\text { processo de autorização }\end{array}$ & Desenvolvimento & $\begin{array}{l}\text { Processo de } \\
\text { credenciamento. }\end{array}$ \\
\hline 9 & $\begin{array}{c}\text { PORTARIA N } \\
2413 \mathrm{DE} \\
07 / 07 / 2005\end{array}$ & $\begin{array}{l}\text { Orientadora para a solicitação da } \\
\text { renovação de reconhecimento de } \\
\text { cursos }\end{array}$ & Desenvolvimento & $\begin{array}{l}\text { Renovação de } \\
\text { reconhecimento }\end{array}$ \\
\hline 10 & $\begin{array}{l}\text { PARECER CNE/ } \\
\text { CES No } 91 \mathrm{DE} \\
10 / 04 / 2008\end{array}$ & $\begin{array}{l}\text { Cobrança de taxas pela emissão } \\
\text { de diploma de graduação }\end{array}$ & Sobrevivência & Cobrança de taxas \\
\hline
\end{tabular}

Figura 110 eventos principais que influenciaram as estratégias da CEAMA

Fonte: Elaborado pelos autores com base nas informações da CEAMA, 2011.

Como afirmam Machado-da-Silva, Fonseca e Fernandes (1999): o ambiente institucional é onde se formam e difundem regras e padrões de procedimentos, que proporcionam à organização legitimidade e apoio contextual. Nas palavras de Coase (1988), não há sentido em se analisar o processo econômico sem a especificação do padrão institucional vigente ao longo deste processo. 
Todas essas mudanças no ambiente institucional (nas normas da educação) ocasionaram um crescimento no número de Instituições de Ensino Superior no Estado do Maranhão. Após a LDB nº 9.394/1996, o número de Instituições de Ensino Superior do Maranhão cresceu rapidamente. Isso se deve, no lado da oferta, às mudanças no ambiente institucional, na referida lei e as demais normas da educação, bem como, sob a ótica da demanda, às exigências do mercado de trabalho.

A partir daí, busca-se, ainda, confirmar a afirmação de Fischer (2001, p. 2): “A discrepância entre velocidade das mudanças do ambiente do setor e a velocidade das mudanças do ambiente interno da organização impõe a assustadora tarefa da mudança organizacional", por meio da identificação e análise das estratégias de crescimento que a Instituição em estudo adotou.

\subsection{IDENTIFICAÇÃO E ANÁLISE DAS ESTRATÉGIAS DA IES ESTUDADA}

Buscando-se atingir o segundo objetivo específico, identificar e analisar as estratégias de crescimento da mantenedora, no período estudado, sob a ótica da teoria institucional, foram realizadas entrevistas a fim de verificar qual o grau de relação/ influência do ambiente institucional e do mercado com a IES.

No que diz respeito à estratégia e estruturação da organização, o respondente A afirma que em 2000, havia um boom no segmento da educação em decorrência da enorme quantidade de alunos que não tinham acesso ao ensino público. Era muito fácil captar alunos; os preços praticados eram extremamente vantajosos para as IES e havia uma margem de lucro bastante razoável. Passados 5 anos, em 2004, o cenário mudou, com aumento de novas IES competindo pelo mesmo alunado, agora formado basicamente pelos recém-egressos do ensino médio. As mensalidades caíram, as margens também e a sustentabilidade começou a ficar ameaçada. São implantados mecanismos de avaliação externa pelo MEC que poderão dificultar a sobrevivência de entidades que não primem pela qualidade.

Após decorridos 10 anos da sua fundação, a situação tornou-se ainda mais crítica, dado que a captação de alunos é cada vez mais difícil face à concorrência, especialmente da educação a distância (com preços muito mais competitivos) reduzindo ainda mais as margens. Os resultados dos mecanismos de avaliação externos começam a impactar a vida das IES, seja pelo fraco desempenho alcançado pelos alunos nos exames ENADE, bem como pela restrição ao lançamento de novos cursos para as IES que estiverem com resultados fracos. Somados a 


\section{AS MUDANÇAS LEGAIS NO AMBIENTE INSTITUCIONAL DO SETOR DE EDUCAÇÃO E AS \\ ESTRATÉGIAS DE CRESCIMENTO DE UMA INSTITUIÇÃO DE ENSINO SUPERIOR \\ DOI: http://dx.doi.org/10.5007/1983-4535.2013v6n1p83}

esses fatores, foi constatado que há expressivo grau de inadimplência e evasão. Deste modo, em muitos momentos, a estratégia passa a ser a de sobrevivência, i.e., atingir o ponto de equilíbrio e manter-se em atividade.

Percebe-se neste caso a confirmação do que Fachin e Mendonça (2003) identificaram, ao afirmarem que as forças ambientais condicionam a ação organizacional ao intuito de sobreviver e institucionaliza-se, estando à institucionalização ligada à necessidade de sobrevivência, de reconhecimento social e de adaptação a interesses existentes no ambiente.

De acordo com o respondente B, a IES, preocupada em oferecer um serviço de qualidade com preços competitivos, garantiu a sua credibilidade junto à comunidade maranhense; consequentemente aumentou a demanda para os Cursos Superiores oferecidos e com a implantação de novos cursos, enquanto o respondente $\mathrm{C}$ afirma que academicamente, os resultados demonstram que a IES não obteve inovações no que tange ao ensino aprendizagem e às suas práticas formativas. Do ponto de vista de estratégia de crescimento, é visível que, em termos de clientes, houve um aumento significativo (haja vista os dados do histórico da IES e número de egressos); no entanto, a sustentabilidade experimentou um declínio nos últimos anos. Já o respondente D diz que o crescimento da IES se deu em razão de dois pontos principais: o primeiro foi o concomitante crescimento da demanda por ensino superior no Brasil e particularmente no Estado do Maranhão. Iniciando seus trabalhos em março de 2000, a FAMA buscou sempre a excelência na prestação de serviços educacionais, o que a posicionou como uma das melhores faculdades do Estado do Maranhão. Isso contribuiu para o seu constante crescimento ao longo dos anos.

Entende-se, portanto, que a IES cresceu em termos de serviços oferecidos, ou seja, quantitativamente houve crescimento organizacional, porém, há evidências de que sua sustentabilidade, em razão de problemas de ordem administrativo-acadêmica, ainda não precisamente diagnosticados, foi afetada negativamente, necessitando de novo planejamento.

No que diz respeito ao que incentivou o crescimento da Instituição de Ensino Superior, como já abordado, no início, o período de elevadas taxas de crescimento da demanda chegou ao fim, em virtude de um número elevado formado por pessoas mais velhas que não tinham acesso ao ensino superior e a falta de concorrência. O respondente A entende que o crescimento da IES, nos seus dez anos de existência, deu-se em razão de um planejamento acadêmico com vistas às necessidades do mercado de trabalho e o oferecimento de um ensino de qualidade, nesse sentido, o respondente $\mathrm{B}$ relata que, indiferente ao resultado alcançado, o 


\section{AS MUDANÇAS LEGAIS NO AMBIENTE INSTITUCIONAL DO SETOR DE EDUCAÇÃO E AS \\ ESTRATÉGIAS DE CRESCIMENTO DE UMA INSTITUIÇÃO DE ENSINO SUPERIOR \\ DOI: http://dx.doi.org/10.5007/1983-4535.2013v6n1p83}

que incentivou a IES em busca pelo crescimento foi a demanda reprimida de mercado, ou seja, havia, no final da década de 90. Já para o respondente $\mathrm{D}$, houve claro espírito empreendedor, por parte de seu fundador, no crescimento e manutenção da IES.

Dessa forma, entende-se que o crescimento foi incentivado por variáveis do ambiente institucional. No que diz respeito em que medida a LDB $N^{\circ}$ 9.394/ 1996 incentivou e influenciou no surgimento, desenvolvimento e crescimento da Instituição de Ensino Superior, o respondente A diz que a lei permitiu a presença maciça do setor privado na educação superior. Ou seja, a LDB foi principal condicionante do surgimento e estruturação desta e da maior parte das IESs em atuação no Brasil.

O respondente $\mathrm{B}$ entende que a LDB serviu de orientadora para os procedimentos acadêmicos das Instituições de Ensino Superior, traçou as diretrizes necessárias para o bom funcionamento da IES. Além do mais, serviu de base para que as IES elaborassem seu Plano de Desenvolvimento Institucional - PDI e o seu Projeto Político Pedagógico Institucional PPPI, documentos essenciais para o funcionamento de uma IES que deseja formar cidadãos responsáveis e profissionais competentes para o mercado de trabalho.

Enfim, a nova LDB acabou dando mais autonomia às IES particulares e incentivando o surgimento de novas instituições. Ela foi aprovada em um cenário caracterizado, principalmente, por uma rearticulação liberal, conservadora e balizada pela defesa do ideário da flexibilização, desregulamentação, privatização e, conseqüentemente, da reverência ao mercado. Essa legislação foi, ainda, consubstanciada por uma sucessão de decretos que a antecedem, redirecionando o paradigma da educação e da escola no Brasil por meio da ênfase numa concepção mercadológica de produtividade, eficiência e qualidade total (LISITA; PEIXOTO, 2001).

No que diz respeito à forma que o mercado estimulou a expansão da IES, segundo o respondente $\mathrm{A}$, há uma forte tendência das organizações somente contratarem profissionais com nível superior, seja no setor privado ou público, forçando as pessoas a buscarem esse tipo de formação. Para o respondente B, no momento em que o mercado exigiu profissionais com determinadas formações, as IES tiveram, necessariamente, que se preparar para atender esse mercado com a implantação de cursos superiores capazes de formar profissionais aptos para esse mercado. Para o respondente D conta que, como toda empresa privada, as IES privadas tendem a aumentar ou diminuir suas operações de acordo com o comportamento do mercado. No caso da FAMA, o mercado está em constante expansão, já que as universidades públicas 


\section{AS MUDANÇAS LEGAIS NO AMBIENTE INSTITUCIONAL DO SETOR DE EDUCAÇÃO E AS \\ ESTRATÉGIAS DE CRESCIMENTO DE UMA INSTITUIÇÃO DE ENSINO SUPERIOR \\ DOI: http://dx.doi.org/10.5007/1983-4535.2013v6n1p83}

não aumentam suas vagas em níveis necessários a atendê-lo, o que proporciona uma fatia cada vez maior para as privadas.

Acredita-se que a forte tendência das organizações em contratar profissionais com nível superior força as pessoas a buscarem formação superior e a partir do momento em que o mercado começou a exigir profissionais com determinadas formações, as IES tiveram que se preparar para atender o mercado com a implantação de cursos superiores capazes de formar profissionais aptos para esse mercado, ou seja, "quem dita a escolha do curso é o mercado" e como toda empresa privada, as IES privadas tendem a aumentar ou diminuir sua oferta e cursos conforme a dinâmica do mercado. Ou seja, há a observância dos princípios de mercado.

No que diz respeito a como as Leis, as Normas e os Decretos contribuem para a manutenção da IES e para o crescimento da mesma, o respondente A entende que eles servem como regulação do Ensino Superior. As IES que não se pautarem por essas leis e normas não se mantêm no mercado. Ao passo que, aquelas que seguem rigorosamente essas regras tendem a se manterem e crescerem, apesar de outros condicionamentos que o Ministério da Educação impõe às Faculdades, a exemplo do Exame Nacional de Desempenho dos Estudantes ENADE que determina, com outros insumos, o conceito final da IES, mas segundo o respondente D, a criação do PROUNI mediante a isenção de impostos federais favoreceu a sobrevivência das IES, que passaram a ofertar vagas ociosas em troca dessa isenção.

Em relação às Estratégias de Crescimento que a IES adotou, o respondente A entende que a estratégia da IES é de manutenção no segmento. Procura-se atender os padrões de qualidade do MEC e alavancar os resultados nos exames ENADE, para que a IES possa continuar ofertando os cursos existentes e pleitear novos, enquanto o respondente B relatou que em boas oportunidades, adotou-se a expansão geográfica da IES para outro município Imperatriz -, a implantação de novos cursos em áreas diversificadas, como área da Saúde foram algumas das estratégias de crescimento que a FAMA adotou, e, para o respondente C, por se tratar de uma empresa familiar e gerida por sócios com interesses pessoais distintos, há que se ressaltar que as estratégias foram falhas, pois visavam à sustentação desses interesses, e, o respondente D afirma que utilizaram-se estudos de mercado para determinar as estratégias de captação de alunos além de buscar sempre melhorar os serviços no intuito de manter os alunos em sala de aula, aliando isso a uma administração de recursos otimizada e profissional, maximizando os lucros para reinvestimentos. 
Após verificar os 5 movimentos da firma propostos por Cardoso, Bomtempo e Pinto Junior (2006, p. 74), busca-se alcançar o terceiro objetivo específico "Analisar a dinâmica do crescimento da IES a partir das mudanças institucionais ocorridas". Verifica-se, então, que houve crescimento por combinação horizontal, expansão geográfica e diversificação.

Os idealizadores da Faculdade, convictos de que é através da educação, do domínio do conhecimento e da formação para a cidadania que pode ser garantida a cada pessoa a oportunidade e o direito de alcançar a sua realização plena, bem como impulsionar o desenvolvimento da sociedade e dos povos, conservando, transmitindo e enriquecendo seus valores e sua cultura, propuseram-se ao desafio de implantar, em São Luís, capital do Estado do Maranhão, uma IES capaz de preencher, com qualidade, lacunas observadas no quadro da oferta de educação superior no Estado.

A FAMA iniciou suas atividades em 2000 com o Curso de Administração, com habilitação em Análise de Sistemas e o Curso de Turismo. No mesmo ano, o terceiro curso a ser autorizado foi de Letras, Licenciatura Plena, com as habilitações: Português e Literaturas de Língua Portuguesa; Espanhol e Literaturas de Língua Espanhola; e, Inglês e Literaturas de Língua Inglesa. Logo em seguida, foram autorizados os cursos de Secretariado Executivo Bilíngue e o curso de Ciências Contábeis. Em 2001 as habilitações do curso de Administração: Gestão Hospitalar, Gestão Hoteleira e Marketing, finalmente, em 2002 o Curso Normal Superior, com as habilitações Licenciatura para Anos Iniciais do Ensino Fundamental e Licenciatura para Educação Infantil.

De acordo com os resultados da pesquisa, se chegou à figura 1, que mostra os movimentos de crescimento da FAMA.

Verifica-se que, ao longo dos anos, a FAMA aumentou o número de alunos significativamente. Porém, no ano de 2009 houve uma queda. A explicação para a queda no quantitativo de alunos pode estar relacionada com a entrada de novos concorrentes e com o fim da demanda de alunos que não conseguiram entrar nas IES públicas. Outra razão pode ter sido a ausência de atratividade de alguns cursos como o de Turismo, que era uma "onda" quando foi criado e depois praticamente desapareceu do mercado. Em 2010 volta a crescer. É esperado um crescimento ainda maior para 2011, visto a abertura de novos cursos de graduação e cursos superiores tecnólogos. 


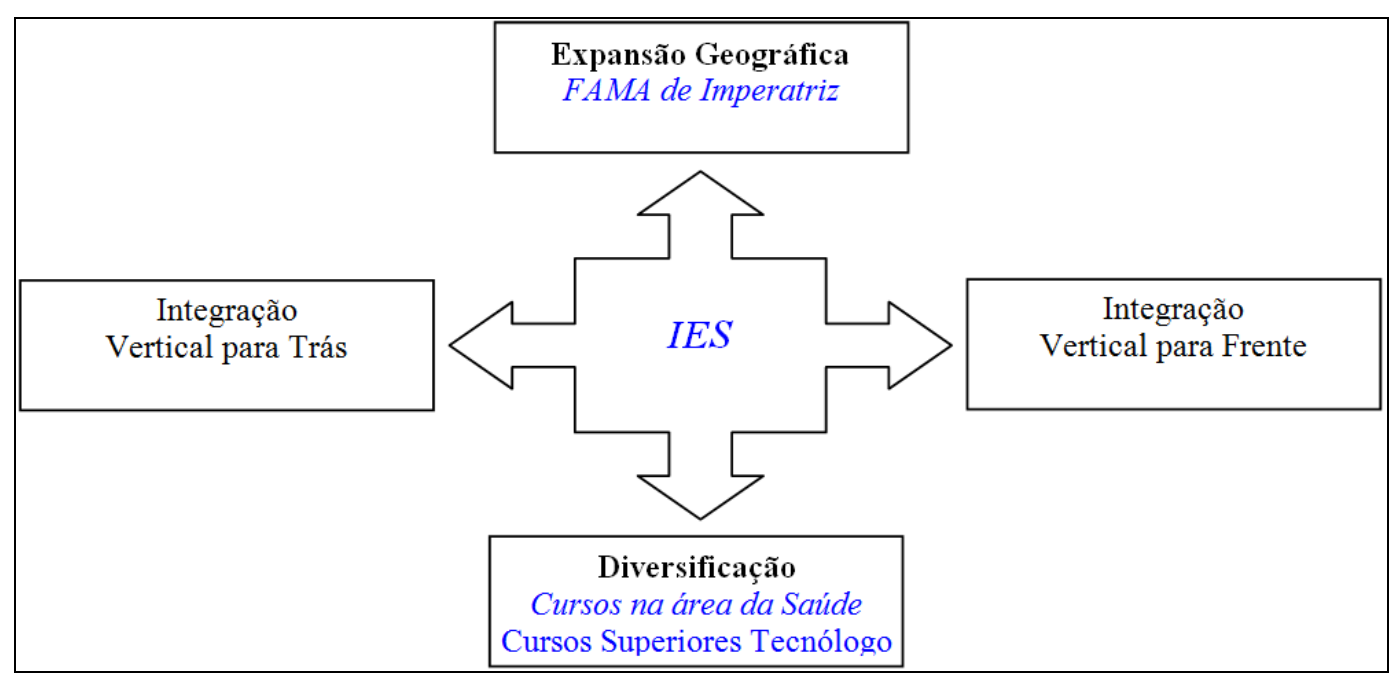

Figura 2 Os Movimentos de Crescimento da CEAMA

Fonte: Adaptada de Cardoso, Bomtempo e Pinto Junior (2006). Elaborada pelos autores com base nas informações da FAMA (2010).

O segundo movimento estratégico identificado foi o de diversificação relacionada, a partir de 2001, caracterizado pela abertura de cursos de extensão. Outro movimento estratégico de crescimento foi o de diversificação relacionada, a FAMA em São Luís começou a ofertar a partir de 2002 cursos de pós-graduação, especialização lato sensu nas áreas de: educação, negócios, saúde, turismo e engenharia, caracterizando-se como uma estratégia de crescimento de diversificação relacionada e não relacionada.

A partir de 2009, A FAMA passou a criar grupos de pesquisas, o que caracteriza-se também como diversificação relacionada.

Objetivando ampliar o leque de suas ações, a CEAMA criou, no município de Imperatriz, a mantida Faculdade Atenas Maranhense de Imperatriz, oferecendo os cursos de graduação em Turismo (Conceito CR), e Administração, com as seguintes habilitações: Administração Hospitalar, Gestão de Negócios e Sistemas de Informação Gerencial (Conceito B) na avaliação do MEC. Esses cursos foram autorizados através das Portarias no 1.390 , de 4 de julho de 2001 e $\mathrm{n}^{\circ}$. 1.911, de 22 de agosto de 2001, respectivamente, e pelas Portarias de Reconhecimento $n^{\circ}$. 88/2006, de 12/01/2006 - D.O.U. $n^{\circ}$. 10, de 13/01/2006, referentes ao Curso de Administração e no . 123/2006, de 30/05/2006 - D.O.U. no. 104, de 01/06/2006, do Curso de Turismo.

Essa estratégia de crescimento do mantenedor CEAMA denomina-se expansão geográfica, corroborando as idéias de Cardoso, Bomtempo e Pinto Junior (2006). Verifica-se, também, que ao longo dos anos, a Faculdade Atenas Maranhense de Imperatriz utilizou-se da estratégia de crescimento por combinação horizontal relacionada, visto que, aumentou o 
número de alunos significativamente. Porém, a partir do ano de 2006 houve uma queda. A explicação para a queda no quantitativo de alunos pode estar relacionada com a entrada de novos concorrentes e com o fim da demanda de alunos que não conseguiram entrar nas IES públicas. Outra razão pode ter sido a ausência de atratividade de alguns cursos como o de Turismo, que era uma "onda" quando foi criado e depois praticamente desapareceu do mercado.

Outro movimento estratégico de crescimento foi o de diversificação relacionada, em 2002 quando a FAMA de Imperatriz abriu as primeiras turmas de cursos de extensão em diversas áreas do conhecimento, voltado para os alunos, professores e comunidade.

Percebeu-se que a mantenedora CEAMA não só trabalha com estratégias de crescimento, mas, também, busca modificar esse cenário a cada oportunidade que o ambiente interno ou externo proporciona, oferecendo novos cursos a fim de expandir o leque de suas ações, contribuindo assim, para o desenvolvimento como um todo da Instituição.

\section{CONCLUSÕES}

Este trabalho teve como objetivo geral analisar a relação das mudanças ocorridas no ambiente institucional do setor de educação superior com as estratégias da Instituição de Ensino Superior Centro de Ensino Atenas Maranhense.

A metodologia da pesquisa produziu dados qualitativos aonde os dados foram coletados junto às pessoas relacionadas diretamente com o ambiente pesquisado, o que permitiu compreender em profundidade o tema e o cenário pesquisado.

Observou-se que os resultados da análise sugerem que essa relação é de influência, visto que, o ambiente é composto de regras, padrões que determinam como as Instituições devem se comportar no ambiente.

Foi após 1996, período em que a Lei de Diretrizes e Bases da Educação Nacional sofreu grande reformulação dando margem ao aparecimento de novas Instituições Ensino Superior, através da facilidade de abertura de IES, e também, através de várias outras normas da educação brasileira que foram criadas e que vieram para facilitar e melhorar alguns aspectos do ensino, pesquisa e extensão do Ensino Superior do Brasil, mas, acabaram também dificultando em outros aspectos. Então, entende-se que só a partir de 1996 que muitas IES foram criadas e a organização em estudo, o Centro de Ensino Atenas Maranhense - CEAMA, 
fundado em 1999 pôde utilizar de estratégias de desenvolvimento, crescimento e sobrevivência para se manter no mercado.

As mudanças no ambiente são muitas vezes impostas pelos órgãos reguladores, sugerindo que dele surjam forças de transformações sobre as organizações, que são influenciadas pelo ambiente econômico, político, social, tecnológico e cultural, que por sua vez, emergem forças de transformação sobre o campo de atuação das IES e essas por sua vez engendram novas formas de atuação sobre esses ambientes.

Cada organização elabora estratégias próprias, respeitando as regras impostas pelo ambiente em que se inserem, e, o seu comportamento resulta, dentre outras variáveis, da influência de pressões exercidas para que a organização se conforme a essas regras e normas, guiando seus comportamentos, os quais tenderão a ser compatíveis com as forças institucionais. Essas organizações estão posicionadas passivamente a sucumbir a pressões coercitivas institucionais e normativas, a fim de obter o apoio de partes interessadas.

Fica claro que aconteceram mudanças no ambiente institucional devido às mudanças nas normas do setor de educação, e que, com isso houve um crescimento no número de IES privadas no Brasil, e no caso de estudo, o Maranhão, que cresceu rapidamente, visto os números apresentados nos resultados da pesquisa.

As mudanças no ambiente institucional ocasionaram não só um crescimento no número de Instituições de Ensino Superior no Estado do Maranhão, mas tiveram condicionantes que não permitiam uma expansão maior. Os dados da pesquisa mostraram a rápida expansão das IES privadas, ao mesmo tempo em que, no período analisado, apenas uma nova IES pública surgiu no estado.

O mercado, por sua vez, também tem significativa influência na estratégia da IES, já que indica as mudanças pelo lado da demanda, fazendo com que as IES se adaptem a tais mudanças.

Conclui-se, portanto, que a mantenedora, o Centro de Ensino Atenas Maranhense CEAMA utilizou estratégias de crescimento, por combinação horizontal, expansão geográfica e diversificação. Foi identificado, também, que a organização utilizou estratégias de sobrevivência, especialmente nos momentos de queda ou estabilização da demanda, que implica queda na receita.

Desse modo é possível vislumbrar como se deu seu crescimento. Academicamente houve crescimento no aumento do nível de qualidade de sua gênese, ou seja, qualitativamente 
em termos de formação, teve uma progressão visível e administrativamente, cresceu no número de clientes alcançados desde a sua origem até o momento em questão, indissociavelmente com o aspecto de sustentabilidade financeira.

Dessa forma, pode-se inferir que as estratégias da IES foram claramente condicionadas por variáveis do ambiente institucional. Destaca-se, neste caso, o isomorfismo regulador que refere-se às regras e leis; o normativo, a internalização do padrão de conduta; mas principalmente o cognitivo, que é o conjunto de valores socialmente aceitos que os atores concebem como realidade na consolidação da legitimação.

\section{REFERÊNCIAS}

ALPERSTEDT, G. D.; MARTIGNAGO, G.; \& FIATES, G. G. S. O processo de adaptação estratégica de uma instituição de ensino superior sob a ótica da teoria institucional. Revista de Ciências da Administração, v. 8, n.15, jan/ jun. 2006.

BARDIN, L. Análise de conteúdo. Lisboa: Edições 70, 2002.

BARRETO, F. C. S.; \& SCHWARTZMAN, J. Ensino superior no Brasil: crescimento e alternativas. Disponível em: www.nesp.unb.br/polrhs/Temas/Ensino_Superior_no_Brasil.pdf. Acesso em: 20 ago. 2010.

BRASIL. Lei de diretrizes e bases da educação nacional. Lei número 9394, 20 de dezembro de 1996. Disponível em: <http://www.portal.mec.gov.br/arquivos/pdf/ldb.pd>. Acesso em: 10 ago. 1996.

CARDOSO, L. G.; BOMTEMPO, J. V.; \& PINTO JUNIOR, H. Q. Compreendendo o crescimento das firmas: ferramentas de análise baseadas em Chandler e Penrose. Revista Organização \& Sociedade, v.13 - n.37 - abr./jun. 2006.

CARNALL, C. Managing change in organizations.London: Prentice-Hall, 1995.

CASTRO, M. H. M. Estado e mercado na regulação da educação superior. Disponível em: $<$ http://www.schwartzman.org.br/simon/desafios/8regulacao.pdf. Acesso em: 15 ago. 2010.

COASE, R. The firm, the market and the law. Chicago: University of Chicago Press, 1988.

COLLINS, J; \& HUSSEY, R. Pesquisa em administração: um guia prático para alunos de graduação e pós-graduação. 2. ed. Porto Alegre: Bookman, 2005.

CRUBELLATE, J. M.; GRAVE, P. S.; \& MENDES, A. A. A questão institucional e suas implicações para o pensamento estratégico. Revista de Administração Contemporânea. v. 8. Edição Especial. 2004. 
DIMAGGIO, P. J; POWELL, W. W. Jaula de ferro revisitada: isomorfismo institucional e racionalidade coletiva nos campos organizacionais. Artigo originalmente publicado em “American Sociological Review”, em 1983. In Caldas, M. P.; Bertero, O. (Coordenadores) (Van de Ven, A. H. et al.). Teoria das Organizações. Série Revista de Administração de Empresas Clássicos. São Paulo: Atlas, 1983.

ESTEVES, P. C. L. Fatores determinantes de mudanças na estrutura competitiva do sistema de ensino superior de Santa Catarina. 154f. Tese de doutorado (Pós Graduação em Engenharia de Produção). Universidade Federal de Santa Catarina. Florianópolis. 2007.

FACHIN, R. C.; MENDONÇA, R. C. de. Selznick: uma visão da vida e da obra do precursor da perspectiva institucional na teoria organizacional. In: VIEIRA, M. M. F.; CARVALHO, C. A. (Orgs.) Organizações, instituições e poder no Brasil. Rio de Janeiro: Ed. FGV, p.29-45, 2003.

FACUldade ATENAS MARANHENSE. Projeto Político Pedagógico Institucional PPPI. Disponível em: <http:// http://www.fama.br/images/stories/pdf/ppi.pdf $>$. Acesso em 20 out. 2010.

FACULDADE ATENAS MARANHENSE DE IMPERATRIZ. Projeto Político Pedagógico Institucional - PPPI. Disponível em:

$<$ http://www.famaitz.edu.br/home_add/PPPI_FAMA_MEC.pdf $>$. Acesso em 30 dez. 2010

FARINA, E. M. M. Q.; AZEVEDO, P. F.; SAES, M. S. M. Competitividade: mercado, estado e organizações. São Paulo: Editora Singular, 1997.

FISCHER, A. Mudança organizacional na universidade: o caso da UNOESC - campus de Videira - SC. 159f. Dissertação (Pós Graduação em Engenharia da Produção). Universidade Federal de Santa Catarina. Florianópolis. 2001.

FONSECA, V. S.; MACHADO-DA-SILVA, C. L. Conversação entre abordagens da estratégia em organizações. Organizações \& Sociedade, v. 9, n. 25, p. 93-110, set-dez. 2002.

LISITA, V. M. S. S.; PEIXOTO, A. J. (Org) Formação de professores: políticas concepções e perspectivas. 1. ed. Goiânia, Goiás: Alternativa, 2001.

MACHADO-DA-SILVA, C.; FONSECA, V. S.; FERNANDES, B. H. R. Mudanças e estratégia nas organizações: perspectivas cognitiva e institucional. In: VIEIRA, M. M. F.; OLIVEIRA, L. M. B. (Org.). Administração contemporânea: perspectivas estratégicas. São Paulo: Atlas, 1999.

MINISTÉRIO DA JUSTIÇA. Cartilha - Instituições Privadas de Ensino Superior. 2007. Disponível em: <http://www.prsp.mpf.gov.br/prdc/especiais/cartilhaIPES.pdf.>. Acesso em: 05 ago. 2007.

MINTZBERG, H. Criando organizações eficazes: estruturas em cinco configurações./ Henry Mintzberg; tradução Ailton Bomfim Brandão. - 2. ed. - São Paulo: Atlas, 2003. 
MOISÉS FILHO, J. G. Qualidade de ensino e eficiência técnica no ensino superior privado: o caso do distrito federal. Dissertação de Mestrado em Administração da Universidade de Brasília. Brasília - DF. 2006.

MORAES, M. C. B. Aspectos essenciais à consolidação de um modelo de gestão para instituições de ensino superior de administração privadas, em ambientes competitivos: um estudo qualitativo em instituições do Rio e São Paulo. 2001. 203f. Tese (Doutorado em Engenharia de Produção) UFSC, Florianópolis. 2001.

PORTO, C.; RÉGNIER, K. Ensino superior no mundo e no Brasil - condicionantes, tendências e cenários para o horizonte 2003-2025. Brasília, DF. 2003.

RIAZ, S. The global financial crisis: an institutional theory analysis. Critical Perspectives on International Business, v. 5, n. 1/2, p. 26-35, 2009.

SCHNEIDER, A. B.; CARNEIRO, M. L.; SERRA, F. A. R.; FERREIRA, M. Estratégia Competitiva: Michael Porter 30 anos depois. Revista de Administração da UFSM, v. 2, p. 338-369, 2009.

SCOTT, W. R. Institutions and organizations.London: Sage Publications, 2001.

SELZNICK, P. Leadership in administration. Nova Iorque, Free Press, 1957.

VASCONCELOS, F.; CYRINO, A. Vantagem competitiva: os modelos teóricos atuais e a convergência entre estratégia e teoria organizacional. Revista de Administração de Empresas.v. 40, n. 4, out./dez. 2000.

WOLCOTT, H. F. Transforming qualitative data: description, analysis, and interpretation.Thousand Oaks: Sage Publications, 1994.

ZUCKER, L. G. Institutional theories of organizations. Annual Review of Sociology, v. 13, p. 443-464, 1987. 